\title{
Effect of Indigenous Drug Administration (KARELA) on Different Parameters Studied Among Healthy and NIDDM Subjects: A Hospital Based Study
}

\section{Parul Gupta *1, Ajay kumar Srivastava ${ }^{2}$.}

${ }^{* 1}$ Ph.D. Scholar, Department of Biochemistry, GSVM medical college, Kanpur (UP), India.

2 Professor and Head, Department of Biochemistry, GSVM medical college, Kanpur (UP), India.

\section{ABSTRACT}

Background: Diabetes mellitus is a group of metabolic disorders with one common manifestation: hyperglycaemia. Chronic hyperglycaemia causes damage to the eyes, kidneys, nerves, heart and blood vessels. The rationale behind this study is to see the effect of Momordica charantia on different carbohydrate and oxidative stress parameters in blood/ serum and to correlate its effect on these parameters among diabetic patients.

Objectives- 1. To see the effect of Momordica charantia on different carbohydrate and lipid parameters in blood/ serum 2. To correlate its effect on these parameters among diabetic patients.

Materials and Methods: It was a hospital based prospective study conducted for a period of 8 months from September 2013- April 2014 in LLR hospital and diabetic clinic of GSVM medical college, Kanpur (UP). A total of 180 study participants were included in the study which consists of 90 diabetic patients and 90 healthy individuals. The investigation reports were collected from pathology laboratory of the college for both diabetic and normal subjects. The parameters which were studied includes plasma glucose levels, glycosylated hemoglobin $(\mathrm{HbAlc})$, catalase, gluthatione peroxidase before conducting the study prior consent of the subjects is taken. Selected subjects were advised to take medicinal plants/substances (karela) from last one month of the study to see its effect. Epi-info software was used. And both paired and unpaired student't' test were applied for analysis.

Conclusion: present study showed a significant change in plasma glucose level and increasing anti-oxidant activity which counteracts hyperglycemia when karela drug powder was administrated. Observation suggest that Karela posses the hypoglycaemic effect.

KEY WORDS: Diabetes, Hyperglycemia, M omordica Charantia.

Address for correspondence: Dr. Parul Gupta, Ph.D. Scholar, Department of Biochemistry, GSVM medical college, Kanpur (UP), India. M obile no.: +919956305882, E-Mail: parul2080@ gmail.com

\begin{tabular}{|c|c|c|}
\hline \multicolumn{3}{|c|}{ Online Access and Article Informtaion } \\
\hline \multirow{2}{*}{$\begin{array}{c}\text { Quick Response code } \\
\text { Dol: } 10.16965 / \text { ijims.2016.127 }\end{array}$} & \multicolumn{2}{|c|}{$\begin{array}{l}\text { International Journal of Integrative Medical Sciences } \\
\text { www.imedsciences.com }\end{array}$} \\
\hline & $\begin{array}{l}\text { Received: 07-06-2016 } \\
\text { Reviewed: 07-06-2016 }\end{array}$ & $\begin{array}{l}\text { Accepted: 14-06-2016 } \\
\text { Published: 30-06-2016 }\end{array}$ \\
\hline Source of Funding: Self & \multicolumn{2}{|c|}{ Conflicts of interest: None } \\
\hline
\end{tabular}

\section{BACKGROUND}

Diabetes mellitus is a group of metabolic disorders with one common manifestation: hyperglycemia. Chronic hyperglycemia causes damage to the eyes, kidneys, nerves, heart and blood vessels. The etiology and pathophysiology leading to the hyperglycemia, however, are markedly different among patients with diabetes mellitus, dictating different prevention strategies, diagnostic screening methods and treatments. The adverse impact of hyperglycemia and the rationale for aggressive treatment have recently been reviewed [1]. Type 2 diabetes 
mellitus (formerly called NIDDM, type II or adult-onset) accounts for 90 - 95\% of all cases. It is characterized by insulin resistance in peripheral tissue and an insulin secretory defect of the beta cell $[2,3]$. This is the most common form of diabetes mellitus and is highly associated with a family history of diabetes, older age, obesity and lack of exercise. Insulin resistance and hyperinsulinemia eventually lead to impaired glucose tolerance. Defective beta cells become exhausted, further fuelling the cycle of glucose intolerance and hyperglycemia. The etiology of type 2 diabetes mellitus is multifactorial and probably genetically based, but it also has strong behavioral components. Out of these two types, the incidence of Type-2 DM is very high amongst Indians with $94-98 \%$ of Indian diabetics belonging to this group. The number of detected cases of DM reflects only the tip of the iceberg, because in India there are a larger number of undetected cases than of detected cases. Various methods have been employed to treat diabetes mellitus which includes chemical, dietary modifications and use of parts of certain medicinal plants. The chemical interaction includes Oral hypoglycemic drugs and insulin Therapy in Type II diabetes mellitus [4].

The dietary modifications include alterations in energy giving nutrients and supply of sufficient vitamins and minerals. Previous studies have shown that bitter melon (M omordica charantia)( karela) [5-8], have been reported that lower the blood glucose level, improved the carbohydrate metabolism, rich in iron, bitter melon has twice the beta carotene of broccoli, twice the calcium of spinach, twice the potassium of bananas, and contains vitamins $C$ and $B 1$ to 3 , phosphorus and good dietary fibre. It is believed to be good for the liver and has been proven by western scientists to contain insulin like substances, possesses anti-oxidant properties, acts as an anti-tumour agent, and inhibit HIV-1 infection and are effective hypolipidemic agent in normals and diabetes mellitus. Bitter melon (momordica charantia), also known as bitter gourd, bitter apple, bitter cucumber, karolla, and karela, is a vegetable cultivated in tropical areas, including India, Asia, South America, and Africa. It is yellow orange with a bumpy exterior resembling a gherkin and is bitter by edible. Momordica charantia Linn (Karela) has been reported to have significant effective hypoglycaemic properties.

Recently, anti-oxidant properties are also illustrated by some researchers [9], showing a significant increase in Antioxidant enzymes like catalase, superoxide dismutase and glutathione peroxidase [10] on alloxan diabetic rats when treated with bitter melon. Not many studies have been seen in India showing the effect of bitter melon on blood parameters and no studies were conducted in this region regarding this, Therefore, the rationale behind this study is to see the effect of Momordica charantia on different carbohydrate and oxidative stress parameters in blood/serum and to correlate its effect on these parameters among diabetic patients.

\section{MATERIALS AND METHODS}

It was a hospital based prospective study conducted for a period of 8 months from September 2013-April 2014 in LLR hospital and diabetic clinic of GSVM medical college, Kanpur (UP). The study participants consisted of two groups one is the established NIDDM subjects confirmed from investigation and hospital records who were admitted to medicine ward during the study period. Another is the group of normal healthy person which are comprised of medical students and members of departmental staff, relatives and friends of diabetic subject whoever available at the time of data collection. The study participants were taken between the age group of $>=18$ to 60 years. A total of 180 study participants were included in the study which consists of 90 diabetic patients and 90 healthy individuals. Inclusion criteria for diabetic patients are $>=18$ years of age upto 60 years,$>$ 60 years were excluded from the study, no other health condition except diabetes, ward admitted patients. Inclusion criteria for normal healthy subjects are $>=18$ years upto 60 years, no health problems detected. The data collection was done at the end of every month when all the investigation of the diabetic patients was available also the duties of departmental staff and medical students postings are changed every month so it was easy to collect the data. 
To avoid selection bias it was decided to takes normal healthy subjects only on the basis of diabetic patient age, otherwise they were will be difference in number of individuals in age groups, for example if we studied 5 diabetic patients of different age groups, the other group should also match the same group, but if they are not available then priority were given to medical stduents and hospital staff because they are easily available. A total of 58 males and 32 females' diabetic subjects were included while 56 males and 34 females included in normal healthy subjects. The investigation reports were collected from pathology laboratory of the college for both diabetic and normal subjects. The parameters which were studied includes plasma glucose levels, glycosylated hemoglobin (HbAlc), catalase, gluthatione peroxidase.before conducting the study prior consent of the subjects is taken. The permission from head of the department of medicine and pathology were also taken. Selected subjects were advised to take medicinal plants/substances (karela) from last one month of the study to see its effect. The Ethical Committee members of the hospital were briefed about the rationale of the study, nature of the procedures, and the benefits that could be availed. There being neither any ethical considerations nor conflicts of interest, the ethical committee clearance was obtained.

Statistical analysis: Collected data were consolidated on Excel sheets and further analyzed in Epi-info software. Mean along with standard deviation (SD) were calculated for the different parameters at different days of the study. Paired and unpaired student't' test were employed to analyze the effect of drug between matched and unmatched groups. P value $\varangle 0.05$ is considered statistically significant.

\section{RESULTS AND OBSERVATIONS}

Table 1 shows age and sex wise distribution of study subjects, the subjects were male preponderance $62 \%$ in normal while $64 \%$ in NIIDM . Among both the subjects the age groups between $50-60$ years has maximum number of subjects. Followed by $40-49$ years which itself shows either the diabetes was late diagnosed, or the subjects admitted themselves only after symptoms of diabetes.
Table 1: Age and sex wise distribution of study subjects during karela drug administration ( $n=180)$.

\begin{tabular}{|c|c|c|c|c|}
\hline \multirow{2}{*}{ Age (years) } & \multicolumn{2}{|c|}{ Normal subjects $(\mathrm{n}=\mathbf{9 0 )}$} & \multicolumn{2}{c|}{ NIDDM subjects $(\mathrm{n}=\mathbf{9 0})$} \\
\hline \multirow{2}{*}{$>\mathbf{1 8 - 2 9}$} & Male & Female & Male & Female \\
\cline { 2 - 5 } & 9 & 7 & 2 & 0 \\
\hline $\mathbf{3 0 - 3 9}$ & 8 & 3 & 2 & 1 \\
\hline $\mathbf{4 0 - 4 9}$ & 22 & 11 & 17 & 10 \\
\hline $\mathbf{5 0 - 6 0}$ & 17 & 13 & 37 & 21 \\
\hline Total & $56(62.2)$ & $34(37.8)$ & $58(64)$ & $32(36)$ \\
\hline
\end{tabular}

Table 2: Effect on values of studied parameters at different days of continuous Karela drug administration and after withdrawal in Normal subjects.

\begin{tabular}{|c|c|c|c|c|c|}
\hline Sno. & Parameter & $0^{\text {th }}$ day & $30^{\text {th }}$ day & Last month & $\begin{array}{l}15 \text { days after } \\
\text { withdrawal }\end{array}$ \\
\hline 1 & Plasma glucose & $113.33+9.8$ & $\begin{array}{c}108.03+10.64 \\
(4.7 \downarrow) \\
p=0.01\end{array}$ & $\begin{array}{c}104.93 \pm 12.83 \\
(7.4 \downarrow) \\
p=0.02\end{array}$ & $\begin{array}{c}109.5+10.32 \\
(4.4 \uparrow) \\
p=0.02\end{array}$ \\
\hline 2 & $\mathrm{HbAlc}$ & $4.14 \pm 0.25$ & $\begin{array}{c}4.01 \pm 0.26 \\
(3 \downarrow) \\
p=0.04\end{array}$ & $\begin{array}{c}3.99 \pm 0.31 \\
(3.6 \downarrow) \\
p=0.02\end{array}$ & $\begin{array}{c}4.08 \pm 0.17 \\
(2.3 \uparrow) \\
p=0.02\end{array}$ \\
\hline 3 & Hemoglobin & $13.69 \pm 1.2$ & $\begin{array}{c}13.76 \pm 1.08 \\
(0.05 \uparrow) \\
p>0.05\end{array}$ & $\begin{array}{c}13.98 \pm 0.88 \\
(2.09 \uparrow) \\
p=0.03\end{array}$ & $\begin{array}{c}13.96 \pm 0.82 \\
(0.16 \downarrow) \\
p>0.05\end{array}$ \\
\hline 4 & $\begin{array}{l}\text { Gluthatione } \\
\text { peroxidase }\end{array}$ & $16.43+1.10$ & $\begin{array}{c}17.27+1.82 \\
(5 \uparrow) \\
p=0.02\end{array}$ & $\begin{array}{c}17.77 \pm 1.83 \\
(8 \uparrow) \\
p=0.01\end{array}$ & $\begin{array}{l}17+1.53 \\
(4.3 \downarrow) \\
p=0.01\end{array}$ \\
\hline 5 & Catalase & $\begin{array}{c}143.87 \pm 3.74 \\
\&\end{array}$ & $\begin{array}{c}148.13 \pm 7.4 \\
(3 \uparrow) \\
p=0.01\end{array}$ & $\begin{array}{c}151.23+11.51 \\
(5.1 \uparrow) \\
p=0.01\end{array}$ & $\begin{array}{c}149.33 \pm 8.22 \\
(1.3 \downarrow) \\
p>0.05\end{array}$ \\
\hline
\end{tabular}

Table 2 shows the effect of different parameters after continuous karela drug administration in normal subjects. The M ean $\pm S . D, \mathrm{mg} / \mathrm{dl}$ plasma glucose level was found to be $192.09 \pm 32.9$ at Oth day, $186 \pm 27.76$ at 30th day and $177.61 \pm 28.46$ at 60 th day. However, at $15^{\text {th }}$ day after drug withdrawal the value increases significantly by $5.12 \%$. Observation suggest that Karela posses the hypoglycaemic effect.

The Mean $\pm S . D$, glycosylated haemoglobin percentage was found to be $7.13 \pm 0.62$ at $0^{\text {th }}$ day, $6.97 \pm 0.6$ at 30 th day and $6.87 \pm 0.58$ at 60 th day. After 15 days of the drug withdrawal the glycosylated haemoglobin value increased significantly by $0.27 \%$. It seems that karela fruit has effect on glycosylated haemoglobin probably by increasing the utilization of glucose.

The Mean \pm S.D, gm/dl haemoglobin level was found to be $13.39 \pm 1.36$ at 0 th day, $13.4 \pm 1.35$ at 30th day and $13.47 \pm 1.35$ at 60th day. The level increased non significantly by $0.07 \%$ at 30 th day and $0.56 \%$ at 60 th day from the value before 
start of the drug. Observations show that Karela fruit powder has no positive effect on haemoglobin.

The Mean $\pm S . D$, Unit/gm Hb specific activity of GPx (gluthtatione peroxidase) was found to be $11.76 \pm 1.06$ at 0 th day, $13.013 \pm 1.9$ on 30th day and $13.85 \pm 2.85$ on 60 th day. However, it decreased non significantly by $4.5 \%$ on 15 th day after drug. withdrawal from 60th day of drug trial. Observations suggest that Karela possessed antioxidant property by upregulating GPxactivity.

The M ean $\pm S . D$, Unit/gm Hb specific activity of CAT (catalase) was found to be $92.23 \pm 9.98$ at Oth day,

$97.90 \pm 12.35$ on 30th day and $101.07+12.46$ on 60 th day. However, it decreased non significantly by $1.5 \%$ on 15 th day after drug withdrawal from 60 th day of drug trial. Observations suggest that Karela possess antioxidant property by escalating CAT activity. $p$-value $<0.05$ is considered statistically significant

Table 3: Effect on values of studied parameters at different days of continuous Karela drug administration and after withdrawal in NIDDM subjects.

\begin{tabular}{|c|c|c|c|c|c|}
\hline Sno. & Parameter & $0^{\text {th }}$ day & $30^{\text {th }}$ day & Last month & $\begin{array}{l}5 \text { days after } \\
\text { withdrawal }\end{array}$ \\
\hline \multirow{3}{*}{1} & \multirow{3}{*}{ Plasma glucose } & \multirow{3}{*}{$192.09 \pm 32.9$} & $186 \pm 27.76$ & $177.6 \pm 28.46$ & $186.7 \pm 31.9$ \\
\hline & & & $(3.17 \downarrow)$ & $(7.5 \downarrow)$ & $(5.12 \uparrow)$ \\
\hline & & & $p=0,01$ & $p=0.001$ & $p=0.04$ \\
\hline \multirow{3}{*}{2} & \multirow{3}{*}{ HbAlc } & \multirow{3}{*}{$7.13 \pm 0.62$} & $6.97 \pm 0.6$ & $6.87 \pm 0.58$ & $6.89 \pm 0.59$ \\
\hline & & & $(2.3 \downarrow)$ & $(3.6 \downarrow)$ & $(0.27 \uparrow)$ \\
\hline & & & $p=0.02$ & $p=0.001$ & $p=0.04$ \\
\hline \multirow{3}{*}{3} & \multirow{3}{*}{ Hemoglobin } & \multirow{3}{*}{$13.39 \pm 1.36$} & $13.4+1.35$ & $13.47 \pm 1.35$ & $13.45 \pm 1.34$ \\
\hline & & & $(0.07 \uparrow)$ & $(0.56 \uparrow)$ & $p>0.05$ \\
\hline & & & $p>0.05$ & $p>0.05$ & \\
\hline \multirow{3}{*}{4} & \multirow{3}{*}{$\begin{array}{l}\text { Gluthatione } \\
\text { peroxidase }\end{array}$} & \multirow{3}{*}{$11.76 \pm 1.06$} & $13 \pm 1.9$ & $13.85+2.85$ & $14.48 \pm 6.92$ \\
\hline & & & $(10.6 \uparrow)$ & $(17.7 \uparrow)$ & $(4.5 \uparrow)$ \\
\hline & & & $p=0,001$ & $\mathrm{p}=0.001$ & $p>0.05$ \\
\hline \multirow{3}{*}{5} & \multirow{3}{*}{ Catalase } & \multirow{3}{*}{$92.23+9.98$} & $97.9 \pm 12.3$ & $101.07 \pm 12.46$ & $99.5 \pm 8.18$ \\
\hline & & & $(6.2 \uparrow)$ & $(9.6 \uparrow)$ & $(1.5 \downarrow)$ \\
\hline & & & $p=0,01$ & $p=0.01$ & $p>0.05$ \\
\hline
\end{tabular}

Table 3 shows the effect of different parameters after continuous karela drug administration in NIDDM subjects. The Mean \pm S.D, mg/dl plasma glucose level was found to be $192.09 \pm 32.9$ at Oth day, $186 \pm 27.76$ at 30th day and $177.61+28.46$ at 60 th day. However, at $15^{\text {th }}$ day after drug withdrawal the value increases significantly by $5.12 \%$. Observation suggest that Karela posses the hypoglycaemic effect.

The Mean $\pm S . D$, glycosylated haemoglobin percentage was found to be $7.13 \pm 0.62$ at $0^{\text {th }}$ day, $6.97 \pm 0.6$ at 30 th day and $6.87 \pm 0.58$ at 60 th day. After 15 days of the drug withdrawal the glycosylated haemoglobin value increased significantly by $0.27 \%$. It seems that karela fruit has effect on glycosylated haemoglobin probably by increasing the utilization of glucose.

The Mean \pm S.D, gm/dl haemoglobin level was found to be $13.39 \pm 1.36$ at 0 th day, $13.4 \pm 1.35$ at 30th day and $13.47 \pm 1.35$ at 60 th day. But the haemoglobin values non significantly showed negligible change on 15th day after drug withdrawal. Observations show that Karela fruit powder has no positive effect on haemoglobin.

The Mean $\pm S . D$, Unit/gm Hb specific activity of GPx was found to be $11.76 \pm 1.06$ at 0th day, $13.013 \pm 1.9$ on 30th day and $13.85 \pm 2.85$ on 60 th day. However, it decreased non significantly by $4.5 \%$ on 15 th day after drug withdrawal from 60 th day of drug trial. Observations suggest that Karela possessed antioxidant property by upregulating GPx activity.

The Mean \pm S.D, Unit/gm Hb specific activity of CAT was found to be $92.23 \pm 9.98$ at 0 th day, $97.90 \pm 12.35$ on 30th day and $101.07 \pm 12.46$ on 60 th day. However, it decreased non significantly by $1.5 \%$ on 15 th day after drug withdrawal from 60 th day of drug trial. Observations suggest that Karela possess antioxidant property by escalating CAT activity. $p$ - Value $<0.05$ is considered statistically significant.

\section{DISCUSSION}

Diabetes mellitus is a global public health problem of epidemic proportions, and its incidence is on the rise. Worldwide, more than 150 million adults have diabetes, a number the World Health Organization [18] expects to double over the next 20 years. Various methods have been employed to treat diabetes mellitus which includes chemical, dietary modifications and use of parts of certain medicinal plants. In our study we showed the effect of karela drug administration to see the effect on different blood parameters in both normal and NIDDM subjects. Bitter melon (momordica charantia), also known as bitter gourd, bitter apple, bitter cucumber, karolla, and karela, is a vegetable cultivated in tropical areas, including India, Asia, South America, and Africa. It is yellow-orange 
with a bumpy exterior resembling gherkin and is bitter by edible [5]. Bitter melon contains several chemical constituents, including the glycosides mormordin and charantin. Charantin contains mixed steroids with hypoglycemic activity. Another component is the peptide polypeptide-P14. Bitter melon also contains the alkaloid mormordicine. Its seeds contain the abortifacients $\alpha$-mormorcharin and $\beta$ mormordicine, as well as the prymidine nucleoside vicine, the fruit and seeds of bitter melon are thought to exert hypoglycemic effects in normal and diabetic animal models [11].

The specific components charantia, polypeptide $P$ and vicine. Other theoretical actions include extra pancreatic activity, such as increased tissues glucose uptake, liver/muscle glycogen synthesis and decreased glucose-6phosphatase, fructose- 1 and 6 bisphosphotase and enhanced glucose oxidation by enzyme G6PDH pathway. From the present study it was found that after administration of Karela fruit powder for 60 days, the percentage of plasma glucose level declined statistically significant by $7.4 \%$ in normal subjects and by $7.53 \%$ in diabetic subjects. Our results were similar to studies conducted by [12-15] on streptozotocin diabetic animals. Khanna P, Jain SC et. al [7] did Polypeptide-p isolation from the fruit and seeds of Karela and showed a potent hypoglycaemic effect when administered subcutaneously to diabetic rats. Therefore, Karela which is normal ingredient of diet possess the hypoglycaemic properties probably by utilization of plasma glucose. It was found that Karela fruit powder can reduce glycosylated haemoglobin level statistically significant by $3.9 \%$ and by $3.7 \%$ in normal and diabetic subjects.

No such studies were done previously to see these effects. It suggests that Karela drug has property of lowering glycosylated haemoglobin level probably by increasing the utilization of glucose. It was also observed that effect was sustained even 15 days after drug withdrawal statistically significant by $2.3 \%$ in diabetic subjects and $0.75 \%$ in normal subjects. Therefore, polypeptide-p (one of the major constituent of Karela) possessing the hypoglycaemic effect may has longer half life. It was found that the Karela drug had statistically significant effect on haemoglobin both in normal subjects. Statistically significant rise in haemoglobin level was observed in normal subjects but not in diabetic subjects. No similar studies were done previously. Ahmed N, Hassan MR, et al [8] have reported that Karela is rich in iron. So, it can be alleged that Karela drug may possess the property of escalating haemoglobin level. Antioxidant enzymes activities (GPX and CAT) were observed to be upregulated statistically significant by Karela fruit powder administration. The specific activity of GPx increased statistically significant by $17.7 \%$ in diabetics and by $8.1 \%$ in normal subjects. Similarly, the rise of CAT activity statistically significant was $5.1 \%$ (Table $2.3 \&$ graph 2.6) and $9.6 \%$ in diabetic subjects. Our results similar to studies conducted by Sathishsekar D [9], and Asli S, Alaattin S [10] in 2007, showing significant increase in antioxidant enzymes like catalase and glutathione peroxidase on alloxan diabetic rats when treated with bitter melon. It was also observed in present study that these effects were sustained even 15 days after drug withdrawal significantly. A possible antioxidative property of Karela may be attributed to the presence of vitamin $C$ and beta carotene in sufficient amount or because of some other unidentified active principle in it. It has also been shown that Karela possess the properties to improve the hepatic functions $[16,17]$. Thus, it can also help in better utilization of glucose.

\section{CONCLUSION}

Since the main objective of the study was to see the effect of karela drug administration on normal and NIDDM subjects. Following are the observation on different parameters based on our results; The Mean \pm S.D, mg/dl plasma glucose level was found to be $192.09 \pm 32.9$ at Oth day, $186 \pm 27.76$ at 30th day and $177.61 \pm 28.46$ at 60th day.Observation suggest that Karela posses the hypoglycaemic effect. Based on our observation karela fruit has effect on glycosylated haemoglobin probably by increasing the utilization of glucose. Observatio-ns show that Karela fruit powder has no positive effect on haemoglobin. Observations suggest that Karela possessed antioxidant property by upregulating GPx activity. Observations suggest that Karela 
possess antioxidant property by escalating CAT activity. So overall conclusion is drug administration of karela as a treatment plan for NIDDM helps significantly by increasing the activity of anti-oxidants and decreasing the oxidative stress.

Limitations of the study: since it is hospital based study it is itself a limitation. Secondary data are used like reports of patients. Age wise equal proportion of subjects are not distributed the normal subjects are included as per choice, but measures were taken to reduce the selection bias. Socio-demographic profile of study subjects were not included which can further enlighten the study and more meaningful conclusion can be done. Methods of parameters were not properly described.

\section{ACKN OWLEDGEM ENT}

Authors are thankful to department of medicine and pathology who provided their permission to conduct this study, also the college CM S without whom it was difficult to get investigations, and finally the authors are heartiest thankful to the diabetic patients who support us in the study and also the hospital staff and medical students.

\section{REFERENCES}

[1]. American Diabetes Association (ADA): Clinical Practice Recommendations 2013. report of the Expert Committee on the Diagnosis and Classification of Diabetes M ellitus. Diabetes Care Volume 24, Supplement 1, 2013.

[2]. Diabetes Care, Report of the Expert Committee on the Diagnosis and Classification of Diabetes Mellitus. 1997;20(7):1183-97.

[3]. International Diabetes Federation. Diabetes e-Atlas. [July 14]. Available at: http://www.eatlas.idf.org. 2005.

[4]. Kasper, Braunwald, Fauci, Hauser, Longo \& Jameson. Harrison's "Principles of Internal Medicine". Chapter 323 Diabetes M ellitus (Alvin C. Powers). Page. 2152, 2176. 16th edition 2004.

[5]. St Louis, Mo., Wolters Kluwer, Facts and Comparisons: The Review of Natural Products, 1999.

[6]. Lancet; Booth GL, et al. Relation between age and cardiovascular disease in men and women with diabetes compared with non-diabetic people: a population-based retrospective cohort study. 2006;368:29-36.

[7]. Khanna P, Jain SC, Panagariya A, Dixit VP: Hypoglycemic activity of polypeptide-p from a plant source. J Nat Prod 1981;44:648-655.
[8]. Ahmed N, Hassan M R, Halder H, Bennoor KS: Effect of Momordica charantia (Karolla) extracts on fasting and postprandial serum glucose level in NIDDM patients. Bangladesh Med Res Counc Bull 1999;25:11-13.

[9]. Sathishsekar D, Subramanian S. Antioxidant properties of M omordica Charantia (bitter gourd) seeds on Streptozotocin induced diabetic rats. Department of Biochemistry and M olecular Biology, University of Madras, Chennai-25, India; 2005

[10].Asli SEMIZ and Alaattin SEN Antioxidant and chemoprotective properties of Momordica charantia L. (bitter melon) fruit extract Department of Biology, Pamukkale University, 20070 KinikliDenizli, TURKEY. Accepted 5 January, 2007

[11]. M ona, Kumar A, et al. "Biochemical studies on the status of free radical and scavangers of some of the bioactive natural products against urolothiasis", Ph.D. Thesis, University of Kanpur, 2001

[12]. M iura, T., Itoh, C., Iwamoto, N., Kato, M., Kawai, M., Park, S. R. and Suzuki, I., Hypoglycemic activity of the fruit of M omordica charantia in type 2 diabetic mice. J. Nutr. Sci. Vitaminol. (Tokyo), 2001;47:240244.

[13]. Pawa M , M Sc(London), MBA(HSM ), MBBS, FRSM Use of traditional/herbal remedies by Indo-Asian people with type 2 diabetes; Fieldway Medical Centre, Fieldway, New Addington, Croydon, UK, 4 April 2005.

[14]. Tongia, A., Tongia, S. K. and Dave, M., Phytochemical determination, and extraction of Momordica charantia fruit and its hypoglycaemic potentiation of oral hypoglycemic drugs in diabetes mellitus (NIDDM). Indian J. Physiol. Pharmacol., 2004; 48:241-244.

[15]. Shetty, A. K., Kumar, G. S., Sambaiah, K. and Salimath, P. V., Effect of bitter gourd (M omordica charantia) on glycemic status in streptozotocin induced diabetic rats. Plant Foods Hum. Nutr. 2005;60:109112.

[16]. Senanayake GV, M aruyama M, Sakono M, Fukuda $\mathrm{N}$, M orishita T, Yukizaki C, Kawano M, Ohta H. The effects of bitter melon (Momordica charantia) extracts on serum and liver lipid parameters in hamsters fed cholesterol-free and cholesterolenriched diets. Department of Biochemistry and Applied Biosciences, Faculty of Agriculture, University of M iyazaki, M iyazaki 8892192, Japan, 2005.

[17].Yadav UC, Moorthy K, Baquer NZ. Combined treatment of sodium orthovanadate and Momordica charantia fruit extract prevents alterations in lipid profile and lipogenic enzymes in alloxan diabetic rats. Hormone and Drug Research Laboratory, School of Life Sciences, Jawaharlal Nehru University, New Delhi, India; 2004.

[18]. WHO Expert Committee on Diabetes Mellitus: second report. World Health Organ Tech Rep Ser 2012;646:1-80. 